\title{
ANÁLISE BIBLIOGRÁFICA SOBRE SISTEMAS VOLTADOS A NUTRICIONISTAS
}

\author{
Ana Paula Schwambach ${ }^{1}$ \\ Juliana Facchini de Souza ${ }^{2}$ \\ Marcio Jose Sembay ${ }^{3}$ \\ Ingrid Solange Sepúlveda Muñoz ${ }^{4}$
}

Resumo: A análise bibliográfica, consiste em analisar dados e descrever de maneira breve o conteúdo de artigos ou documentos. A análise descrita neste artigo, reforça a importância da tecnologia em ambientes hospitalares, na área nutricional, tanto para pacientes quanto para o profissional atuante. Os sistemas nutricionais visam informações, orientação e a resolução de problemas encontrados utilizando a tecnologia a favor da vida e da saúde. É de extrema importância a saúde nutricional do ser humano, pois é através de um corpo nutrido que a saúde se estabelece. O resultado da pesquisa demostra que existem ferramentas tecnológicas direcionadas para as nutricionistas, mas que ainda requerem um maior estudo e desenvolvimento, principalmente para sistemas especialistas, os quais são capazes de tomar decisões semelhantes a um especialista.

Palavras-chave: Nutrição; Revisão; Sistema; Paciente; Nutricionista.

\footnotetext{
1 Ciência da Computação, Centro Universitário Unifacvest, Brasil. E-mail: anapaulaschw1104@gmail.com.

2 Ciência da Computação, Centro Universitário Unifacvest, Brasil. E-mail: jufacchini1@gmail.com.

${ }^{3}$ Ciência da Computação, Centro Universitário Unifacvest, Brasil. E-mail: m_sembay@yahoo.com.br.

${ }^{4}$ Ciência da Computação, Centro Universitário Unifacvest, Brasil. E-mail: ismunoz3@gmail.com.
} 